\title{
Insulin resistance and cognitive performance in type 2 diabetes - The Maastricht study
}

Citation for published version (APA):

Geijselaers, S. L. C., Sep, S. J. S., Schram, M. T., van Boxtel, M. P. J., Henry, R. M. A., Verhey, F. R. J., Kroon, A. A., Schaper, N. C., Dagnelie, P. C., Kallen, C. J. H. V. D., Stehouwer, C. D. A., \& Biessels, G. J. (2017). Insulin resistance and cognitive performance in type 2 diabetes - The Maastricht study. Journal of Diabetes and Its Complications, 31(5), 824-830. https://doi.org/10.1016/j.jdiacomp.2017.01.020

Document status and date:

Published: 01/05/2017

DOI:

10.1016/j.jdiacomp.2017.01.020

Document Version:

Publisher's PDF, also known as Version of record

Document license:

Taverne

Please check the document version of this publication:

- A submitted manuscript is the version of the article upon submission and before peer-review. There can be important differences between the submitted version and the official published version of record.

People interested in the research are advised to contact the author for the final version of the publication, or visit the DOI to the publisher's website.

- The final author version and the galley proof are versions of the publication after peer review.

- The final published version features the final layout of the paper including the volume, issue and page numbers.

Link to publication

\footnotetext{
General rights rights.

- You may freely distribute the URL identifying the publication in the public portal. please follow below link for the End User Agreement:

www.umlib.nl/taverne-license

Take down policy

If you believe that this document breaches copyright please contact us at:

repository@maastrichtuniversity.nl

providing details and we will investigate your claim.
}

Copyright and moral rights for the publications made accessible in the public portal are retained by the authors and/or other copyright owners and it is a condition of accessing publications that users recognise and abide by the legal requirements associated with these

- Users may download and print one copy of any publication from the public portal for the purpose of private study or research.

- You may not further distribute the material or use it for any profit-making activity or commercial gain

If the publication is distributed under the terms of Article $25 \mathrm{fa}$ of the Dutch Copyright Act, indicated by the "Taverne" license above, 


\title{
Insulin resistance and cognitive performance in type 2 diabetes - The Maastricht study
}

\author{
Stefan L.C. Geijselaers ${ }^{\text {a,b,c,* }}$, Simone J.S. Sep ${ }^{\text {a,b }}$, Miranda T. Schram ${ }^{\text {a,b }}$, Martin P.J. van Boxtel ${ }^{\text {d }}$, \\ Ronald M.A. Henry ${ }^{\mathrm{a}, \mathrm{b}}$, Frans R.J. Verhey ${ }^{\mathrm{d}}$, Abraham A. Kroon ${ }^{\mathrm{a}, \mathrm{b}}$, Nicolaas C. Schaper ${ }^{\mathrm{a}, \mathrm{b}, \mathrm{e}}$, \\ Pieter C. Dagnelie ${ }^{\text {b,e,f }}$, Carla J.H. van der Kallen ${ }^{\mathrm{a}, \mathrm{b}}$, Coen D.A. Stehouwer ${ }^{\mathrm{a}, \mathrm{b}}$, Geert Jan Biessels ${ }^{\mathrm{c}}$ \\ a Department of Internal Medicine, Maastricht University Medical Center +, Maastricht, the Netherlands \\ b CARIM School for Cardiovascular Diseases, Maastricht University, Maastricht, the Netherlands \\ c Department of Neurology, Brain Center Rudolf Magnus, University Medical Center Utrecht, Utrecht, the Netherlands \\ ${ }^{\mathrm{d}}$ Department of Psychiatry and Neuropsychology and MHeNS School for Mental Health and Neuroscience, Maastricht University Medical Center + , Maastricht, the Netherlands \\ e CAPHRI School for Public Health and Primary Care, Maastricht University, Maastricht, the Netherlands \\ ${ }^{\mathrm{f}}$ Department of Epidemiology, Maastricht University, Maastricht, the Netherlands
}

\section{A R T I C L E I N F O}

\section{Article history:}

Received 6 November 2016

Received in revised form 28 January 2017

Accepted 31 January 2017

Available online 12 February 2017

\section{Keywords:}

Type 2 diabetes mellitus

Cognitive performance

Fasting insulin

C-peptide

Insulin resistance

\begin{abstract}
A B S T R A C T
Aims: Type 2 diabetes, hyperinsulinemia, and insulin resistance are associated with cognitive impairment. Experimental studies indicate that insulin signaling in the brain is related to cognitive performance. Here we evaluated whether insulin-related variables contribute to the variance in cognitive performance among individuals with type 2 diabetes.

Methods: A total of 806 individuals with type 2 diabetes (mean age $62 \pm 8$ years, HbA1c $6.9 \pm 1.1 \%$ ) completed a neuropsychological test battery. Insulin-related variables evaluated were: fasting plasma insulin, C-peptide, and the Homeostasis Model Assessment (HOMA2-IR; in individuals without insulin treatment; $\mathrm{n}=641$ ). The unadjusted coefficient of determination $\left(\mathrm{R}^{2}\right)$, obtained from multiple linear regression analyses, was used to estimate the proportion of variance in cognition explained by insulin-related variables. Results: Sex, age, and educational level together explained $18.0 \%\left(\mathrm{R}^{2}\right)$ of the variance in memory function, $26.5 \%$ in information processing speed, and $22.8 \%$ in executive function and attention. Fasting insulin, C-peptide, or HOMA2-IR did not increase the explained variance (maximum $\Delta \mathrm{R}^{2} 0.3 \%, \mathrm{P} \geq 0.14$ ). Similar results were obtained when insulin-related variables were added to models that additionally included glycemic control, cardiovascular risk factors, and depression.

Conclusions: Our results show that measures of peripheral insulin resistance are unrelated to cognitive performance among individuals with adequately controlled type 2 diabetes.
\end{abstract}

(c) 2017 Elsevier Inc. All rights reserved.

\section{Introduction}

Type 2 diabetes is known to be associated with cognitive dysfunction. The severity of diabetes-associated cognitive changes varies, ranging from subtle cognitive decrements to mild cognitive impairment and dementia. ${ }^{1}$ Yet it is unclear why individuals with type 2 diabetes develop these cognitive changes. Given the ongoing diabetes epidemic and the increasing life-expectancy of individuals with type 2 diabetes, ${ }^{2}$ there is an urgent need to identify factors that

Conflicts of interest: GJB consults for and receives research support from Boehringer Ingelheim, consults for Takeda Pharmaceuticals, and has received speaker's fees from Eli Lilly. The other authors have no conflicts of interest to declare.

* Corresponding author at: Maastricht University Medical Center +, Department of Internal Medicine, P. Debyelaan 25, P.O. Box 5800, 6202 AZ, Maastricht, the Netherlands. Tel.: + 310433876600 ; fax + 310433875006 .

E-mail address: stefan.geijselaers@gmail.com (S.LC. Geijselaers). contribute to the severity and progression of cognitive problems among individuals with type 2 diabetes.

We recently conducted a systematic review of the literature to examine whether abnormalities in glucose regulation, the hallmark of diabetes, are related to cognitive performance among individuals with type 2 diabetes. ${ }^{3}$ Based on the findings of 86 papers, we concluded that measures of glycemia, particularly glycated hemoglobin (HbA1c) and glucose variability, are negatively, but weakly, associated with cognitive performance. We also noted that, compared to glycemia, far less is currently known about the association of hyperinsulinemia and insulin resistance with cognitive performance among individuals with type 2 diabetes. ${ }^{3}$ This topic is clearly worthy of further study, not only because these insulin-related measures have been found to be inversely associated with cognitive performance in individuals without diabetes (e.g. ${ }^{4-6}$ ), but especially because experimental studies have linked insulin signaling to normal brain functioning, as well as to brain disease. ${ }^{7}$ 
The aim of the present study was to assess whether insulin-related variables (i.e. fasting insulin, C-peptide, and the Homeostasis Model Assessment of Insulin Resistance (HOMA2-IR)) contribute to the variance in cognitive performance among individuals with type 2 diabetes.

\section{Material and methods}

\subsection{Study population}

We used data from The Maastricht Study, an observational prospective population-based cohort study enriched with individuals with type 2 diabetes. The rationale and methodology have been described previously. ${ }^{8}$ In brief, the study focuses on the etiology, pathophysiology, complications, and comorbidities of type 2 diabetes and is characterized by an extensive phenotyping approach. Eligible for participation were all individuals aged between 40 and 75 years living in the southern part of the Netherlands. Participants were recruited through mass media campaigns and from the municipal registries and the regional Diabetes Patient Registry via mailings.

For the present study, cross-sectional data from the first 975 participants with type 2 diabetes were used, who completed the baseline survey between November 2010 and September 2013. Diabetes status was determined by a 75-g oral glucose tolerance test and defined according to the 2006 World Health Organization ${ }^{9}$ diagnostic criteria, as described in more detail before. ${ }^{8}$ Participants were also considered to have type 2 diabetes if they used glucose-lowering medication without a prior diagnosis of type 1 diabetes.

The Maastricht Study was approved by the institutional medical ethical committee (NL31329.068.10) and the Minister of Health, Welfare and Sports of the Netherlands, on the basis of the Health Council's opinion (Permit 131088-105234-PG). All participants gave written informed consent.

\subsection{Insulin-related variables}

The following insulin-related variables were considered in the present study: fasting insulin, C-peptide, and HOMA2-IR. Both insulin and $\mathrm{C}$-peptide were included as they provide similar but complementary information. Specifically, while insulin and C-peptide are secreted in equimolar amounts by the pancreatic $\beta$-cells, C-peptide is not extracted from the circulation by the liver, and hence its half-life is longer than that of insulin, ${ }^{10}$ which might make it a more stable and reliable reflector of insulin secretion. In addition, recent research has shown that C-peptide interacts with insulin and may prevent neuronal loss and cognitive deficits in experimental type 1 diabetes. ${ }^{11}$ All insulin-related variables were based on venous blood samples, which were collected after an overnight fast. Serum and plasma were separated after centrifugation ( $3000 \times \mathrm{g}$ for $15 \mathrm{~min}$ at $4{ }^{\circ} \mathrm{C}$ ) and were stored at $-80{ }^{\circ} \mathrm{C}$ until the assays were performed.

Insulin and C-peptide were quantified on a Meso Scale custom duplex assay (Meso Scale Discovery, Gaithersburg, MD, USA). In short, 96-well plates, with capture antibodies against insulin and C-peptide patterned on distinct spots in the same well, were supplied by the manufacturer. Samples (10 $\mu \mathrm{L} /$ well), detection antibodies, and read buffer for electrochemiluminescence were applied according to manufacturer's instruction, and plates were read using a SECTOR ${ }^{\circledR}$ 2400 Imager. Detection ranges of the assay were $35-25,000 \mathrm{pg} / \mathrm{mL}$ for insulin and $70-50,000 \mathrm{pg} / \mathrm{mL}$ for C-peptide. Interassay coefficients of variation for insulin and C-peptide were $10.1 \%$ and $8.2 \%$, respectively. Insulin and C-peptide were converted from $\mathrm{pg} / \mathrm{mL}$ to $\mathrm{pmol} / \mathrm{L}$ using a molar mass of $5808 \mathrm{~g}$ for insulin and $3010 \mathrm{~g}$ for C-peptide.

Insulin resistance was estimated from fasting insulin and glucose by the Homeostasis Model Assessment of Insulin Resistance (HOMA2-IR) and calculated by using the HOMA2 calculator (version 2.2.3 for Windows; available from https://www.dtu.ox.ac.uk/ homacalculator). The fasting plasma glucose concentrations required to calculate HOMA2-IR were measured in venous blood samples with the enzymatic hexokinase method using two automatic analyzers (i.e. the Beckman Synchron LX20 [Beckman Coulter Inc., USA] for samples obtained between November 2010 and April 2012, and the Roche Cobas 6000 [Roche Diagnostics, Mannheim, Germany] for samples obtained thereafter). Because the HOMA2-IR has not been validated for individuals using exogenous insulin, ${ }^{12}$ calculations were limited to those not treated with insulin.

\subsection{Cognitive performance}

A concise (30 min) neuropsychological test battery was applied to assess cognitive performance. ${ }^{8}$ Test scores were standardized and divided into three cognitive domains (i.e. memory function, executive function and attention, and information processing speed), as detailed in the Supplementary Material. In short, memory function was evaluated using the Verbal Learning Test by calculating the mean of total immediate and delayed recall scores. The composite score for information processing speed was derived from the Stroop Color Word Test Part I and II, the Concept Shifting Test Part A and B, and the Letter-Digit Substitution Test. Executive function and attention was assessed by the Stroop Color Word Test Part III and the Concept Shifting Test Part C. Raw test scores were standardized using the mean and the standard deviation of the subpopulation with type 2 diabetes rather than the whole Maastricht Study population. Where appropriate, individual test scores were inverted so that higher scores indicated better cognitive performance.

\subsection{Covariates}

Fasting serum total cholesterol and high-density lipoprotein (HDL) cholesterol were measured with standard enzymatic methods on the same auto-analyzers as used to measure glucose. HbA1c was measured with ion-exchange high performance liquid chromatography. Questionnaires were used to gather information on, among others, diabetes duration, smoking behavior (never/former/current), and history of cardiovascular disease (CVD), as described in detail before. ${ }^{8}$ Personal interviews were conducted to evaluate medication $\mathrm{use}^{8}$ and determine educational level, which was categorized as low, intermediate, or high. ${ }^{13}$ Suspected presence of a depression was assessed with the Mini International Neuropsychiatric Interview (MINI). ${ }^{8}$ Waist circumference was measured in duplicate midway between the lower rib margin and the iliac crest at the end of expiration and recorded to the nearest $0.5 \mathrm{~cm}$. Systolic and diastolic blood pressures were calculated as the average of at least three consecutive blood pressure readings (Omron 705IT, Omron Corporation, Kyoto, Japan) performed after a minimum of 10 min seated rest. Data on 24-h ambulatory blood pressure monitoring (WatchBP03, Microlife AG, Widnau, Switzerland $)^{8}$ were only available in a subset of participants $(\mathrm{n}=712)$.

\subsection{Statistical analyses}

All statistical analyses were performed with use of SPSS version 20.0 for Windows and version 23.0 for Mac (IBM SPSS, IBM Corp, Armonk, NY, USA). Fasting insulin concentrations and HOMA2-IR values were transformed with the natural logarithm prior to analyses because of non-normal distribution. A two-sided p-value $<0.05$ was considered statistically significant, except for interaction analyses, where the significance level was set at 0.10 .

Multiple linear regression analyses were performed to test whether insulin-related variables contributed to the variance in cognitive performance among individuals with type 2 diabetes. To this end, the unadjusted coefficient of determination, referred to as $R$-squared $\left(R^{2}\right)$ and reflecting explained variance, was used as effect estimate. More specifically, fasting insulin, C-peptide, and HOMA-IR 
were each combined with possible confounders in three subsequent regression models: model 1 demographic factors (i.e. age, sex, and educational level); model 2 demographic factors and glycemic control (i.e. fasting glucose and HbA1c); and model 3 demographic factors, glycemic control, cardiovascular risk factors (i.e. waist circumference, total/HDL-cholesterol ratio, use of lipid-modifying medication, systolic and diastolic blood pressure, use of antihypertensive medication, and smoking behavior), and the presence of a depression. The incremental change in explained variance was assessed and statistically tested by the corresponding F-tests. In addition to changes in $\mathrm{R}^{2}$, we also report standardized regression coefficients that reflect the associations between insulin-related variables and cognitive performance.

We used multiplicative interaction terms to examine whether any association between insulin-related variables and cognitive performance differed between individuals previously diagnosed with diabetes and those newly diagnosed at study entry, by gender, or by age. Non-linearity of the associations between fasting insulin or C-peptide and cognitive performance was explored by entering linear and quadratic terms of the mean-centered variables to the regression model, as at least fasting insulin concentrations have been shown to be quadratically associated with dementia risk in older individuals. ${ }^{14}$

As a sensitivity analysis, we re-examined the association between fasting insulin and cognitive performance after the exclusion of individuals treated with insulin and after additional exclusion of individuals treated with oral glucose-lowering medication that potentially enhances insulin secretion (i.e. dipeptidyl peptidase-4 inhibitors, sulfonylurea derivatives, and glucagon-like peptide-1 analogues). We also checked whether outliers influenced the results by excluding individuals with fasting insulin or C-peptide concentrations that were three standard deviations away from the sample mean. Finally, to test the robustness of our findings, analyses were rerun with adjustment for 24-h ambulatory blood pressure instead of office blood pressure ( $\mathrm{n}=712$ ), as well as with additional adjustment for diabetes duration $(n=570)$ or history of CVD.

\section{Results}

Of the first 975 individuals with type 2 diabetes who completed the baseline survey of The Maastricht Study, 114 (11.7\%) had no, or incomplete, data on measures of cognitive performance, and 22 (2.3\%) had missing data on fasting insulin or C-peptide concentrations. An additional 38 (3.9\%) individuals were excluded from the present analyses because of missing data on covariates, resulting in a final study population of 806 individuals. Differences in demographic, clinical, and diabetes-related characteristics between individuals with complete and incomplete data are depicted in Table A1 (Supplementary Material). Notably, those excluded were generally older and less well educated.

Characteristics of the final study population are presented in Table 1 . The mean age was $62 \pm 8$ years, $67.2 \%$ of the individuals were men, and 119 (14.8\%) were newly diagnosed with diabetes at study entry. Individuals with known type 2 diabetes had a median disease duration of 6 years and their overall glycemic control was good with a mean HbA1c of $7.0 \%$ (53 mmol/mol). Mean HbA1c concentrations were $6.2 \%(44 \mathrm{mmol} / \mathrm{mol})$ in individuals with newly diagnosed diabetes.

\subsection{Fasting insulin, C-peptide, and cognitive performance}

Table 2 shows the variance in cognitive performance explained by fasting insulin and C-peptide concentrations above and beyond that explained by other factors (i.e. demographics, glycemic control, cardiovascular risk factors, and depression). Demographic factors alone (Model 1) explained one-fifth to one-fourth of the variance in cognitive performance, with varying contributions across domains
Table 1

Characteristics of the study population $(n=806)$.

\begin{tabular}{|c|c|}
\hline Age (years) & $62 \pm 8$ \\
\hline Sex (male/female) & $542 / 264$ \\
\hline Educational level, low/middle/high & $215 / 357 / 234(26.7 \% / 44.3 \% / 29.0 \%)$ \\
\hline Diabetes duration (years) ${ }^{\mathrm{a}}$ & $6[3-12]$ \\
\hline HbA1c (\%) & $6.9 \pm 1.1$ \\
\hline $\mathrm{HbA1c}(\mathrm{mmol} / \mathrm{mol})$ & $52 \pm 12$ \\
\hline Fasting glucose $(\mathrm{mmol} / \mathrm{l})$ & $7.9 \pm 2.0$ \\
\hline Fasting insulin $(\mathrm{pmol} / \mathrm{l})$ & $85[53-134]$ \\
\hline C-peptide $(\mathrm{nmol} / \mathrm{l})$ & $0.85 \pm 0.43$ \\
\hline Glucose-lowering medication, any type ${ }^{\mathrm{b}}$ & $628(91.4 \%)$ \\
\hline Insulin & $165(24.0 \%)$ \\
\hline Oral glucose-lowering medication & $591(86.0 \%)$ \\
\hline Alpha-glucosidase inhibitors & $0(0 \%)$ \\
\hline Biguanides & $562(81.8 \%)$ \\
\hline DPP-4 inhibitors & $51(7.4 \%)$ \\
\hline Sulfonylurea derivatives & $168(24.5 \%)$ \\
\hline Thiazolidinediones & $8(1.2 \%)$ \\
\hline Glucagon-like peptide- 1 analogues & $7(1.0 \%)$ \\
\hline Waist circumference (cm) & $105 \pm 13$ \\
\hline Total cholesterol $(\mathrm{mmol} / \mathrm{L})$ & $4.5 \pm 1.0$ \\
\hline HDL-cholesterol (mmol/L) & $1.3 \pm 0.4$ \\
\hline Triglycerides (mmol/L) & $1.5[1.1-2.1]$ \\
\hline Lipid-modifying medication & $594(73.7 \%)$ \\
\hline Systolic blood pressure $(\mathrm{mmHg})^{\mathrm{c}}$ & $142 \pm 18$ \\
\hline Diastolic blood pressure $(\mathrm{mmHg})^{\mathrm{c}}$ & $77 \pm 9$ \\
\hline Hypertension $^{\mathrm{d}}$ & $669(83.0 \%)$ \\
\hline Antihypertensive medication & $577(71.6 \%)$ \\
\hline Smoking behavior, never/former/current & $223 / 455 / 128(27.7 \% / 56.5 \% / 15.9 \%)$ \\
\hline Prior cardiovascular disease & $218(27.0 \%)$ \\
\hline Current depression & $76(9.4 \%)$ \\
\hline
\end{tabular}

Data are presented as mean $\pm \mathrm{SD}$, median [IQR], or $\mathrm{n}(\%)$.

Abbreviation: DPP-4 = dipeptidyl peptidase-4.

a Data available for $\mathrm{n}=570$.

b Data available for individuals with known type 2 diabetes $(n=687)$.

c Obtained from office blood pressure measurements.

d Hypertension was defined as a systolic blood pressure $\geq 140 \mathrm{mmHg}$ (based on office blood pressure measurements), a diastolic blood pressure $\geq 90 \mathrm{mmHg}$, and/or current use of antihypertensive medication.

(i.e. memory function (18.0\%), information processing speed (26.5\%), executive function and attention $(22.8 \%)$ ). Fasting insulin or C-peptide was not associated with cognitive performance when added to this first model, nor did they increase the total explained variance of the model. Similar results were obtained when they were added to subsequent models with glycemic control (Model 2) and with cardiovascular risk factors and the presence of a depression (Model 3). Specifically, across all models, the maximum increase in explained variance by either fasting insulin or C-peptide was $0.1 \%$ ( $\mathrm{p}$-value for F-tests $\geq 0.48$ ). We did also not observe any quadratic association of insulin or C-peptide with cognitive performance (Table A2, Supplementary Material).

Of note, incorporating measures of glycemic control did not explain more variance in cognitive performance than did demographics alone, whereas the inclusion of cardiovascular risk factors and depression increased the explained variance with $1.1 \%$ to $2.4 \%$. This increase only reached statistical significance for information processing speed ( $\mathrm{p}$-value for F-tests $<0.01$ ).

\subsection{HOMA2-IR and cognitive performance}

Table 3 shows the variance in cognitive performance explained by HOMA2-IR as a marker of insulin resistance in non-insulin treated individuals ( $\mathrm{n}=641$ ). Results for HOMA2-IR were roughly similar to those for insulin and C-peptide in that HOMA2-IR was not associated with cognitive performance and did not lead to an increase in the explained variance in cognition. 
Variance in cognitive performance among individuals with type 2 diabetes explained by fasting plasma insulin and C-peptide concentrations $(\mathrm{n}=806)$.

\begin{tabular}{|c|c|c|c|c|c|c|c|c|c|}
\hline & \multicolumn{3}{|l|}{ Memory function } & \multicolumn{3}{|c|}{ Information processing speed } & \multicolumn{3}{|c|}{ Executive function $\&$ attention } \\
\hline & $\beta(95 \% C I)$ & $R^{2}$ & $\overline{F \text {-test }}$ & $\beta(95 \% C I)$ & $R^{2}$ & $\overline{F \text {-test }}$ & $\overline{\beta(95 \% C I)}$ & $R^{2}$ & $\overline{F-t e s t}$ \\
\hline Model 1: & & $18.0 \%$ & & & $26.5 \%$ & & & $22.8 \%$ & \\
\hline$+(\ln )$ Fasting insulin & $-0.013(-0.076 ; 0.050)$ & $18.0 \%\left(\Delta \mathrm{R}^{2}=0.0 \%\right)$ & 0.69 & $0.002(-0.058 ; 0.062)$ & $26.5 \%\left(\Delta \mathrm{R}^{2}=0.0 \%\right)$ & 0.94 & $0.018(-0.044 ; 0.079)$ & $22.8 \%\left(\Delta R^{2}=0.0 \%\right)$ & 0.57 \\
\hline + C-peptide & $-0.006(-0.069 ; 0.057)$ & $18.0 \%\left(\Delta \mathrm{R}^{2}=0.0 \%\right)$ & 0.85 & $-0.001(-0.061 ; 0.059)$ & $26.5 \%\left(\Delta \mathrm{R}^{2}=0.1 \%\right)$ & 0.97 & $0.004(-0.058 ; 0.065)$ & $22.8 \%\left(\Delta \mathrm{R}^{2}=0.0 \%\right)$ & 0.91 \\
\hline Model 2: & & $18.0 \%$ & 0.84 & & $26.9 \%$ & 0.13 & & $22.8 \%$ & 0.68 \\
\hline$+(\ln )$ Fasting insulin & $-0.011(-0.075 ; 0.054)$ & $18.0 \%\left(\Delta R^{2}=0.0 \%\right)$ & 0.75 & $0.003(-0.058 ; 0.063)$ & $26.9 \%\left(\Delta \mathrm{R}^{2}=0.0 \%\right)$ & 0.93 & $0.014(-0.048 ; 0.077)$ & $22.9 \%\left(\Delta R^{2}=0.0 \%\right)$ & 0.65 \\
\hline + C-peptide & $-0.004(-0.068 ; 0.061)$ & $18.0 \%\left(\Delta \mathrm{R}^{2}=0.0 \%\right)$ & 0.92 & $-0.005(-0.066 ; 0.056)$ & $26.9 \%\left(\Delta \mathrm{R}^{2}=0.0 \%\right)$ & 0.87 & $<0.001(-0.063 ; 0.062)$ & $22.8 \%\left(\Delta \mathrm{R}^{2}=0.0 \%\right)$ & 1 \\
\hline Model 3: & & $19.5 \%$ & 0.11 & & $29.3 \%$ & $<0.01$ & & $24.1 \%$ & 0.14 \\
\hline$+(\ln )$ Fasting insulin & $-0.027(-0.100 ; 0.047)$ & $19.5 \%\left(\Delta \mathrm{R}^{2}=0.1 \%\right)$ & 0.48 & $-0.004(-0.073 ; 0.065)$ & $29.3 \%\left(\Delta \mathrm{R}^{2}=0.0 \%\right)$ & 0.91 & $0.014(-0.058 ; 0.085)$ & $24.1 \%\left(\Delta \mathrm{R}^{2}=0.0 \%\right)$ & 0.70 \\
\hline + C-peptide & $-0.021(-0.096 ; 0.053)$ & $19.5 \%\left(\Delta \mathrm{R}^{2}=0.0 \%\right)$ & 0.58 & $-0.013(-0.083 ; 0.057)$ & $29.3 \%\left(\Delta \mathrm{R}^{2}=0.0 \%\right)$ & 0.72 & $-0.003(-0.076 ; 0.069)$ & $24.1 \%\left(\Delta \mathrm{R}^{2}=0.0 \%\right)$ & 0.93 \\
\hline
\end{tabular}

+ C-peptid $-0.021(-0.096 ; 0.053)$

$19.5 \%\left(\Delta R^{2}=0.0 \%\right)$

0.58

$-0.013(-0.083 ; 0.057)$

$29.3 \%\left(\Delta R^{2}=0.0 \%\right)$

0.72

$-0.003(-0.076 ; 0.069)$

$24.1 \%\left(\Delta \mathrm{R}^{2}=0.0 \%\right)$

coenter $\beta$ (95\% confidence interval), explained variance of the regession model $R^{2}$, amount of variance explained

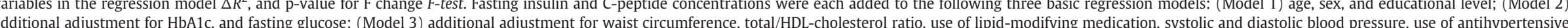

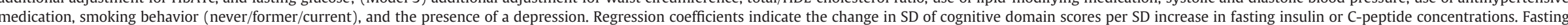
insulin concentrations were transformed with the natural logarithm prior to analyses.

Table 3

Variance in cognitive performance among individuals with type 2 diabetes explained by HOMA2-IR $(\mathrm{n}=641)$.

\begin{tabular}{|c|c|c|c|c|c|c|c|c|c|}
\hline & \multicolumn{3}{|l|}{ Memory function } & \multicolumn{3}{|c|}{ Information processing speed } & \multicolumn{3}{|c|}{ Executive function \& attention } \\
\hline & $\beta(95 \% \mathrm{Cl})$ & $R^{2}$ & $\overline{F-t e s t}$ & $\beta(95 \% C I)$ & $R^{2}$ & $\overline{F-t e s t}$ & $\beta(95 \% \mathrm{Cl})$ & $R^{2}$ & $\overline{F \text {-test }}$ \\
\hline Model 1: & & $16.0 \%$ & & & $25.6 \%$ & & & $20.4 \%$ & \\
\hline$+(\ln )$ HOMA2-IR & $0.020(-0.052 ; 0.092)$ & $16.0 \%\left(\Delta \mathrm{R}^{2}=0.0 \%\right)$ & 0.59 & $0.049(-0.019 ; 0.117)$ & $25.8 \%\left(\Delta \mathrm{R}^{2}=0.2 \%\right)$ & 0.15 & $0.040(-0.030 ; 0.110)$ & $20.6 \%\left(\Delta R^{2}=0.2 \%\right)$ & 0.26 \\
\hline Model 2: & & $16.0 \%$ & 0.98 & & $25.6 \%$ & 0.84 & & $20.5 \%$ & 0.78 \\
\hline$+(\ln )$ HOMA2-IR & $0.020(-0.052 ; 0.093)$ & $16.0 \%\left(\Delta \mathrm{R}^{2}=0.0 \%\right)$ & 0.58 & $0.051(-0.017 ; 0.119)$ & $25.8 \%\left(\Delta R^{2}=0.3 \%\right)$ & 0.14 & $0.039(-0.031 ; 0.110)$ & $20.6 \%\left(\Delta R^{2}=0.2 \%\right)$ & 0.27 \\
\hline Model 3: & & $17.1 \%$ & 0.44 & & $27.8 \%$ & 0.02 & & $21.9 \%$ & 0.25 \\
\hline$+(\ln )$ HOMA2-IR & $0.009(-0.077 ; 0.095)$ & $17.1 \%\left(\Delta \mathrm{R}^{2}=0.0 \%\right)$ & 0.84 & $0.056(-0.024 ; 0.136)$ & $28.0 \%\left(\Delta R^{2}=0.2 \%\right)$ & 0.17 & $0.045(-0.038 ; 0.128)$ & $22.0 \%\left(\Delta R^{2}=0.1 \%\right)$ & 0.29 \\
\hline
\end{tabular}

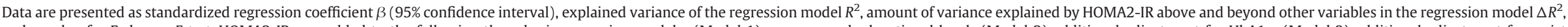

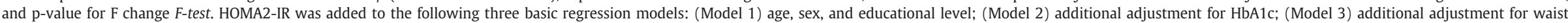

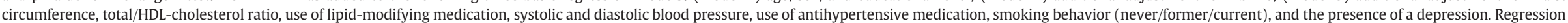
coefficients indicate the change in SD of cognitive domain scores per SD increase in HOMA2-IR. HOMA2-IR was transformed with the natural logarithm prior to analyses. 


\subsection{Interaction analyses}

Interaction analyses showed that age and sex did not clearly modify the null-association of insulin-related variables with cognitive performance (Table A3, Supplementary Material). Likewise, results were similar between individuals with previously and newly diagnosed diabetes (data not shown).

\subsection{Sensitivity analyses}

Because the use of exogenous insulin may affect the association of insulin concentrations with cognitive performance, we reran the analysis in the subgroup of individuals not treated with insulin $(\mathrm{n}=641)$. In this subgroup, the association between fasting insulin and cognitive performance was also non-significant (Table A4, Supplementary Material). Additional exclusion of individuals receiving glucose-lowering medication with insulin secretion stimulating effects ( $n$ excluded $=201$ ) did not impact our findings (data not shown). Likewise, after exclusion of individuals with extreme values of fasting insulin $(n=6)$, C-peptide $(n=9)$, or HOMA2-IR $(n=1)$, the results remained virtually unchanged (data not shown). Alternative adjustment for 24 -h blood pressure and additional adjustment for diabetes duration or a history of CVD did also not materially alter our results (data not shown).

\section{Discussion}

The present study shows that neither HOMA2-IR nor fasting plasma insulin or C-peptide concentrations are associated with cognitive performance among individuals in late middle age with adequately controlled type 2 diabetes.

To our knowledge, this is the largest and most comprehensive study to date examining the association between insulin-related variables and cognitive performance among people with type 2 diabetes. Our results reinforce those of previous smaller studies showing that insulin-related variables are unrelated to cognitive performance ${ }^{15-19}$ and cognitive decline ${ }^{18,20}$ among individuals with diabetes, even in those with less well-controlled diabetes. ${ }^{17} \mathrm{~A}$ few other small studies, ${ }^{21-28}$ some of which evaluated overlapping populations, ${ }^{23-25}$ have reported seemingly contradictory results, but these studies were often conducted in selected populations, for example focusing on individuals with mild cognitive impairment, ${ }^{21,22}$ and did not always adequately control for demographic factors. ${ }^{21,22,26,27}$ Collectively, the currently available data thus strongly suggest that, in a population-based sample of individuals with type 2 diabetes, measures of peripheral insulin resistance are unrelated to cognitive performance.

The lack of an association between peripheral insulin resistance and cognitive performance in type 2 diabetes might be somewhat surprising given that such an association has been established in (middle-aged) individuals without diabetes (e.g. ${ }^{4-6}$ ). The association of insulin resistance with cognitive performance might thus differ by diabetes status, which is supported by two previous studies showing that fasting hyperinsulinemia ${ }^{29}$ and higher HOMA values ${ }^{19}$ are associated with worse cognitive performance ${ }^{19}$ and an increased risk for dementia ${ }^{29}$ among individuals without diabetes, but not in those with diabetes. One potential explanation for this discrepancy lies in the receptor-mediated transport of insulin across the blood-brain barrier, which has been shown to decrease with the degree of insulin resistance. ${ }^{30}$ As a consequence, peripheral insulin may not accurately reflect central (i.e. cerebral) concentrations of insulin in those with diabetes. In addition, it has been suggested that peripheral and cerebral insulin resistance does not necessarily co-exist. ${ }^{31}$ Alternatively, however, the discrepancy between our findings and those of previous studies in people without diabetes could also relate to the potential inaccuracy of fasting insulin and HOMA2-IR as measures of (peripheral) insulin resistance in diabetes, not only because $\beta$-cells often lose their insulin secretion capacity as the disease progresses, but also because oral glucose-lowering medication can enhance insulin secretion. ${ }^{32}$ Note, however, that similar null results were observed when additional adjustments were made for diabetes duration or when analyses were restricted to those individuals not using glucose-lowering medication with insulin secretion stimulating effects.

In a broader context, it is possible that the factors that contribute to cognitive dysfunction among individuals with type 2 diabetes differ from those in the general population. Noteworthy in this regard is our observation that traditional cardiovascular risk factors explained only a marginal amount of variance (i.e. $1.1 \%$ to $2.4 \%$ ) in cognitive performance beyond that explained by demographics, even when we used the 24-h blood pressure data. Although cardiovascular risk factors, such as obesity, hypertension, and dyslipidemia, may be associated with an increased risk of cognitive dysfunction in the general population, ${ }^{33,34}$ a recent review concluded that it remains to be determined whether these factors are also linked to cognitive performance among individuals with type 2 diabetes. ${ }^{35}$ It is conceivable that the earlier detection and more intensive treatment of cardiovascular risk factors in individuals diagnosed with diabetes might limit the potential detrimental effects these factors can have on the brain. Likewise, it is possible that multiple cardiovascular risk factors do not necessarily exert additive effects on the brain. On the contrary, however, the ubiquity of cardiovascular co-morbidities in people with type 2 diabetes could limit the ability to detect associations between cardiovascular risk factors and cognitive performance in these individuals. In addition, previous studies have suggested that cardiovascular risk factors in midlife are more closely associated with late-life than with midlife cognitive performance ${ }^{36}$ and that cardiovascular risk factors, particularly blood pressure, might be non-linearly rather than linearly related to cognitive performance among individuals with type 2 diabetes. ${ }^{37}$ Hence, the relatively small proportion of variance explained by traditional cardiovascular risk factors in the present study does not undoubtedly mean that these factors are irrelevant to cognitive performance in diabetes.

Although we can conclude from our data that measures of peripheral insulin resistance are unrelated to cognitive performance in type 2 diabetes, we cannot preclude the possibility that central insulin resistance may affect cognitive performance. As mentioned above, this is not only because peripheral insulin concentrations may not adequately reflect cerebral concentrations, but also because of the possibility of peripheral insulin resistance being not invariably accompanied by central insulin resistance. ${ }^{31}$ Two recent pilot studies in a small sample of older individuals with type 2 diabetes and age-matched healthy individuals have demonstrated that a single dose of intranasal insulin can acutely improve visuospatial memory performance, ${ }^{38,39}$ highlighting the effects cerebral insulin may have on the brain in diabetes. Experimental studies have identified multiple pathways through which insulin signaling may affect cognitive performance. It, for example, affects synaptic plasticity, modulates neurotransmitter release, and contributes to the glucose availability in the brain. ${ }^{7}$ At the same time, insulin is known to interact with the metabolism of amyloid- $\beta$ and tau, ${ }^{7}$ key proteins in the pathogenesis of Alzheimer's disease. Unfortunately, however, it is currently not possible to measure insulin signaling in the human brain in vivo. Consequently, the role of central insulin signaling in cognitive performance remains elusive.

Strengths of the present study include its relatively large sample size and the use of a comprehensive neuropsychological test battery to assess cognitive performance across multiple domains. The findings discussed above should, however, also be viewed in the light of a few limitations. Most importantly, our study population was characterized by a relatively large proportion of highly-educated (29\%) individuals, a relatively young age (mean age $62 \pm 8$ years), and overall adequate glycemic control (mean HbA1c $6.9 \pm 1.1 \%(52 \pm 12 \mathrm{mmol} / \mathrm{mol})$ ). This seemed partly enhanced by our complete case analysis approach (e.g. for educational level and age, Table A1 (Supplementary 
Material)), and may not only have resulted in slightly underestimated effects, but also somewhat limits the generalizability of our findings. Another limitation might be that the venous blood sampling and cognitive assessment were not performed at the same day. Consequently, we may have missed acute effects of hyperinsulinemia due to intraindividual day-to-day variability in insulin resistance. ${ }^{40}$ In addition, we were unable to fully account for the biphasic nature of fasting insulin concentrations during the pathogenesis of diabetes, where the early phase of diabetes is characterized by hyperinsulinemia and $\beta$-cells become progressively exhausted as the diseases progresses. We believe, however, that these limitations are unlikely to fully explain the null-associations observed in the present study.

\section{Conclusions}

The present study shows that peripheral hyperinsulinemia and insulin resistance are unrelated to cognitive performance among individuals with type 2 diabetes. From an etiological perspective, our findings suggest that peripheral insulin resistance is not involved in cognitive performance among these people, thereby challenging the concept that insulin has cerebral effects, although peripheral and cerebral insulin resistance may not necessarily coincide. From a clinical perspective, our results indicate that measures of peripheral insulin resistance are unlikely to explain the variety of cognitive problems among individuals with diabetes and hence are unlikely to be useful markers to screen individuals with diabetes for cognitive problems or to identify those who are likely to develop such problems. The present study also highlights that the factors that are associated with cognitive performance may differ by diabetes status. This implies that individuals with and without diabetes might benefit from a different approach for the prevention and treatment of cognitive problems. Further studies are warranted to elucidate the effects of central insulin resistance on cognition in diabetes and to adequately address the possibility of central and peripheral insulin resistance being differentially associated with cognitive performance.

\section{Acknowledgments}

\section{Funding}

The research of GJB is supported by grant 2010T073 from the Dutch Heart Association and GJB and SLCG are supported by Vidi grant 91711384 from ZonMw, The Netherlands Organization for Health Research and Development. The Maastricht Study was supported by the European Regional Development Fund via OP-Zuid, the Province of Limburg, the Dutch Ministry of Economic Affairs (grant 310.041), Stichting De Weijerhorst (Maastricht, the Netherlands), the Pearl String Initiative Diabetes (Amsterdam, the Netherlands), the Cardiovascular Center (CVC, Maastricht, the Netherlands), Cardiovascular Research Institute Maastricht (CARIM, Maastricht, the Netherlands), School for Public Health and Primary Care (CAPHRI, Maastricht, the Netherlands), School for Nutrition, Toxicology and Metabolism (NUTRIM, Maastricht, the Netherlands), Stichting Annadal (Maastricht, the Netherlands), Health Foundation Limburg (Maastricht, the Netherlands) and by unrestricted grants from Janssen-Cilag B.V. (Tilburg, the Netherlands), Novo Nordisk Farma B.V. (Alphen aan den Rijn, the Netherlands) and Sanofi-Aventis Netherlands B.V. (Gouda, the Netherlands).

\section{Appendix A. Supplementary data}

Supplementary data to this article can be found online at http://dx. doi.org/10.1016/j.jdiacomp.2017.01.020.

\section{References}

1. Koekkoek PS, Kappelle LJ, van den Berg E, Rutten GE, Biessels GJ. Cognitive function in patients with diabetes mellitus: guidance for daily care. Lancet Neurol. 2015;14: 329-40.

2. Lutgers HL, Gerrits EG, Sluiter WJ, Ubink-Veltmaat LJ, Landman GW, Links TP, et al. Life expectancy in a large cohort of type 2 diabetes patients treated in primary care (ZODIAC-10). PLoS One. 2009;4:e6817.

3. Geijselaers SL, Sep SJ, Stehouwer CD, Biessels GJ. Glucose regulation, cognition, and brain MRI in type 2 diabetes: a systematic review. Lancet Diabetes Endocrinol. 2015;3:75-89.

4. Young SE, Mainous III AG, Carnemolla M. Hyperinsulinemia and cognitive decline in a middle-aged cohort. Diabetes Care. 2006;29:2688-93.

5. Okereke O, Hankinson SE, Hu FB, Grodstein F. Plasma C peptide level and cognitive function among older women without diabetes mellitus. Arch Intern Med. 2005;165:1651-6.

6. Okereke OI, Kurth T, Pollak MN, Gaziano JM, Grodstein F. Fasting plasma insulin, C-peptide and cognitive change in older men without diabetes: results from the Physicians' Health Study II. Neuroepidemiology. 2010;34:200-7.

7. Cholerton B, Baker LD, Craft S. Insulin, cognition, and dementia. Eur J Pharmacol. 2013;719:170-9.

8. Schram MT, Sep SJ, van der Kallen CJ, Dagnelie PC, Koster A, Schaper N, et al. The Maastricht Study: an extensive phenotyping study on determinants of type 2 diabetes, its complications and its comorbidities. Eur J Epidemiol. 2014;29:439-51.

9. World Health Organisation. Definition and diagnosis of diabetes mellitus and intermediate hyperglycemia: report of a WHO/IDF consultation. Available at: http://www.idf.org/webdata/docs/WHO_IDF_definition_diagnosis_of_diabetes. pdf2006. [Last accessed: July 19, 2015].

10. Horwitz DL, Starr JI, Mako ME, Blackard WG, Rubenstein AH. Proinsulin, insulin, and C-peptide concentrations in human portal and peripheral blood. J Clin Invest. 1975;55:1278-83.

11. Sima AA, Kamiya H. Is C-peptide replacement the missing link for successful treatment of neurological complications in type 1 diabetes? Curr Drug Targets. 2008;9:37-46.

12. Wallace TM, Levy JC, Matthews DR. Use and abuse of HOMA modeling. Diabetes Care. 2004;27:1487-95.

13. Spauwen PJ, van Eupen MG, Kohler S, Stehouwer CD, Verhey FR, van der Kallen CJ, et al. Associations of advanced glycation end-products with cognitive functions in individuals with and without type 2 diabetes: the maastricht study. I Clin Endocrinol Metab. 2015;100:951-60

14. Peila R, Rodriguez BL, White LR, Launer LJ. Fasting insulin and incident dementia in an elderly population of Japanese-American men. Neurology. 2004:63:228-33.

15. Manschot SM, Biessels GJ, de Valk H, Algra A, Rutten GE, van der Grond J, et al. Metabolic and vascular determinants of impaired cognitive performance and abnormalities on brain magnetic resonance imaging in patients with type 2 diabetes. Diabetologia. 2007;50:2388-97.

16. Tiehuis AM, Mali WP, van Raamt AF, Visseren FL, Biessels GJ, van Zandvoort MJ, et al. Cognitive dysfunction and its clinical and radiological determinants in patients with symptomatic arterial disease and diabetes. J Neurol Sci. 2009;283: $170-4$

17. Akisaki T, Sakurai T, Takata T, Umegaki H, Araki A, Mizuno S, et al. Cognitive dysfunction associates with white matter hyperintensities and subcortical atrophy on magnetic resonance imaging of the elderly diabetes mellitus Japanese elderly diabetes intervention trial (J-EDIT). Diabetes Metab Res Rev. 2006;22:376-84.

18. Imamine R, Kawamura T, Umemura T, Umegaki H, Kawano N, Hotta M, et al. Does cerebral small vessel disease predict future decline of cognitive function in elderly people with type 2 diabetes? Diabetes Res Clin Pract. 2011;94:91-9.

19. Benedict C, Brooks SJ, Kullberg J, Burgos J, Kempton MJ, Nordenskjold R, et al. Impaired insulin sensitivity as indexed by the HOMA score is associated with deficits in verbal fluency and temporal lobe gray matter volume in the elderly. Diabetes Care. 2012;35:488-94.

20. Reijmer YD, van den Berg E, de Bresser J, Kessels RP, Kappelle LJ, Algra A, et al. Accelerated cognitive decline in patients with type 2 diabetes: MRI correlates and risk factors. Diabetes Metab Res Rev. 2011;27:195-202.

21. Gao Y, Xiao Y, Miao R, Zhao J, Zhang W, Huang G, et al. The characteristic of cognitive function in Type 2 diabetes mellitus. Diabetes Res Clin Pract. 2015;109: 299-305.

22. Abbatecola AM, Lattanzio F, Molinari AM, Cioffi M, Mansi L, Rambaldi P, et al. Rosiglitazone and cognitive stability in older individuals with type 2 diabetes and mild cognitive impairment. Diabetes Care. 2010;33:1706-11.

23. Umegaki H, Kawamura T, Kawano N, Umemura T, Kanai A, Sano T. Factors associated with cognitive decline in elderly diabetics. Dement Geriatr Cogn Disord Extra. 2011:1:1-9.

24. Umegaki H, Kawamura T, Umemura T, Kawano N. Factors associated with cognitive decline in older adults with type 2 diabetes mellitus during a 6-year observation. Geriatr Gerontol Int. 2015;15:302-10.

25. Umegaki H, Kawamura T, Mogi N, Umemura T, Kanai A, Sano T. Glucose control levels, ischaemic brain lesions, and hyperinsulinaemia were associated with cognitive dysfunction in diabetic elderly. Age Ageing. 2008;37:458-61.

26. Yanagawa M, Umegaki H, Uno T, Oyun K, Kawano N, Maeno H, et al. Association between improvements in insulin resistance and changes in cognitive function in elderly diabetic patients with normal cognitive function. Geriatr Gerontol Int. 2011;11:341-7.

27. Suzuki M, Umegaki H, Uno T, Oyun O, Mogi N, Maeno H, et al. Association between insulin resistance and cognitive function in elderly diabetic patients. Geriatr Gerontol Int. 2006;6:254-9. 
28. Pearce KL, Noakes M, Wilson C, Clifton PM. Continuous glucose monitoring and cognitive performance in type 2 diabetes. Diabetes Technol Ther. 2012;14: 1126-33.

29. Luchsinger JA, Tang MX, Shea S, Mayeux R. Hyperinsulinemia and risk of Alzheimer disease. Neurology. 2004;63:1187-92.

30. Kern W, Benedict C, Schultes B, Plohr F, Moser A, Born J, et al. Low cerebrospinal fluid insulin levels in obese humans. Diabetologia. 2006;49:2790-2.

31. Banks WA, Owen JB, Erickson MA. Insulin in the brain: there and back again. Pharmacol Ther. 2012;136:82-93.

32. DeFronzo RA. Pharmacologic therapy for type 2 diabetes mellitus. Ann Intern Med. 2000;133:73-4.

33. Plassman BL, Williams Jr JW, Burke JR, Holsinger T, Benjamin S. Systematic review: factors associated with risk for and possible prevention of cognitive decline in later life. Ann Intern Med. 2010;153:182-93.

34. Van den Berg E, Kloppenborg RP, Kessels RP, Kappelle LJ, Biessels GJ. Type 2 diabetes mellitus, hypertension, dyslipidemia and obesity: A systematic comparison of their impact on cognition. Biochim Biophys Acta. 2009;1792:470-81.
35. Feinkohl I, Price JF, Strachan MW, Frier BM. The impact of diabetes on cognitive decline: potential vascular, metabolic, and psychosocial risk factors. Alzheimers Res Ther. 2015;7:46

36. Reijmer YD, van den Berg E, Dekker JM, Nijpels G, Stehouwer CD, Kappelle LJ, et al. Development of vascular risk factors over 15 years in relation to cognition: the Hoorn Study. J Am Geriatr Soc. 2012;60:1426-33.

37. Spauwen PJ, van Boxtel MP, Verhey FR, Kohler S, Sep SJ, Koster A, et al. Both Low and High 24-Hour Diastolic Blood Pressure Are Associated With Worse Cognitive Performance in Type 2 Diabetes: The Maastricht Study. Diabetes Care. 2015;38:1473-80.

38. Novak V, Milberg W, Hao Y, Munshi M, Novak P, Galica A, et al. Enhancement of vasoreactivity and cognition by intranasal insulin in type 2 diabetes. Diabetes Care. 2014;37:751-9.

39. Zhang H, Hao Y, Manor B, Novak P, Milberg W, Zhang J, et al. Intranasal insulin enhanced resting-state functional connectivity of hippocampal regions in type 2 diabetes. Diabetes. 2015;64:1025-34.

40. Jayagopal V, Kilpatrick ES, Jennings PE, Hepburn DA, Atkin SL. Biological variation of homeostasis model assessment-derived insulin resistance in type 2 diabetes. Diabetes Care. 2002;25:2022-5. 